\title{
If the Engineering Literature Fits, Use It! Student Application of Grey Liter- ature and Engineering Standards
}

\section{Chelsea Leachman, Washington State University}

Chelsea Leachman is the engineering librarian at Washington State University. She obtained here Masters of Library and Information Science from the University of Wisconsin-Milwaukee in 2011. She has a background in science and engineering. She received her Bachelor of Science in Environmental Science with a minor in geology from the University of Idaho 2007.

\section{Prof. Jacob William Leachman, School of Mechanical and Materials Engineering, Washington State University}

Jacob Leachman is an Assistant Professor in the School of Mechanical and Materials Engineering at Washington State University (WSU). He initiated the HYdrogen Properties for Energy Research (HYPER) laboratory at WSU in 2010 with the mission to advance the Technology Readiness Level (TRL) of hydrogen systems. He received a B.S. degree in Mechanical Engineering from the University of Idaho in 2005 and a M.S. degree in 2007. His master's thesis has been adopted as the foundation for hydrogen fueling standards and custody exchange, in addition to winning the Western Association of Graduate Schools Distinguished Thesis Award for 2008. He completed his Ph.D. in the Cryogenic Engineering Laboratory at the University of Wisconsin-Madison in 2010 on the visco-plastic flow of hydrogenic materials for the fueling of fusion energy machines. He has conducted guest research in the Physical and Chemical Properties of Fluids Group at the National Institute of Standards and Technology (NIST), and the Pellet Fueling of Fusion Plasmas Group at Oak Ridge National Laboratory (ORNL). 


\title{
If the Engineering Literature Fits, Use It! Student Application of Grey Literature and Engineering Standards
}

\begin{abstract}
The ACRL information literacy standards include the need for students to use information effectively to accomplish a specific purpose. To use information for a specific purpose students should have an ability to differentiate the types of information available, assess the relevance and credibility of the source to their application, and then apply the information within the context of their writing. Engineering students are usually aware of monographs and periodicals from introductory library instruction but are unfamiliar with grey literature and engineering standards. To address this need, collaboration between library and engineering instruction for a senior level capstone mechanical engineering design course was created. The course consisted of 3 independent sections of approximately 18 students each that were randomly paired and assigned projects from the same pool of 10 system-level experiments. The students were tasked with developing a full analysis and report of the system-level performance of their respective experiment. Library instruction occurred during the second lecture of class and consisted of a fifty minute overview presentation followed by two hours of work time. All sections were presented information types as five different categories: monographs, scholarly articles, grey literature, standards, and multimedia. One section of the class was randomly selected and presented information types placed into contextual uses within example sections of a report and assigned a worksheet requiring them to find sources specific to their project and list them within the report section they planned to implement the literature. The efficacy of this pedagogical change to contextualize examples followed by immediate application was assessed by measuring the frequency and type of citations used by all 3 sections of the class. Citation analysis found a statistically insignificant $7 \%$ increase in total number of citations used by the test section students. Although the utilization of engineering standards did not increase, the use of grey literature in the test section increase $83 \%$ compared with the two control sections taught by the same engineering faculty. Furthermore the test section decreased their use of multimedia information. Two subsequent sections of the course taught by other engineering faculty are also compared. This provides a preliminary indication that contextualizing library instruction by information type increases the diversity of literature utilized by engineering students. The overall credibility of citations utilized by students in their reports is likely to increase if this diversity increases the use of grey literature and standards.
\end{abstract}

Introduction

The organization responsible for accrediting college and university engineering programs, ABET, specifies "incorporating appropriate engineering standards" $[1]$ as a key criterion for curriculum assessment. As a result, many engineering courses have made use of engineering standards an explicit outcome of course syllabi. The American Society of Mechanical Engineers (ASME) specifies

"A standard can be defined as a set of technical definitions and guidelines, "how to" instructions for designers, manufacturers, and users. Standards promote safety, reliability, productivity, and efficiency in almost every industry that relies on engineering 
components or equipment. Standards can run from a few paragraphs to hundreds of pages, and are written by experts with knowledge and expertise in a particular field who sit on many committees" "[2].

Engineering standards have also been found to increase innovation in engineering by providing a common baseline allowing design efforts to be focused on more contemporary issues ${ }^{[3]}$. Despite this pivotal role in engineering education, literature documenting library education methods for increasing use of these standards is desperately lacking.

Standards are typically classified as a form of grey literature. The definition most commonly accepted for grey literature is from the Third International Conference on Grey Literature in Luxembourg:

"Information produced on all levels of government, academics, business and industry in electronic and print formats not controlled by commercial publishing i.e. where publishing is not the primary activity of the producing body" ${ }^{\text {"[4] }}$.

Clearly, identifying the difference between grey literature, standards, and other forms of literature is an important issue for practicing engineers. In a survey by Waters, Kasuto, and NcNaughton ${ }^{[5]}$ corporate engineers responded that the most important types of information were standards and technical reports (grey literature).

Despite the documented industry ranking, academic engineering faculty rank scholarly journal articles as the most important information form ${ }^{[6]}$. This ranking has likely guided traditional library instruction to focus on journal database subscriptions that students typically do not have access to after graduation. Although the skills of literature searching are transferable to databases and general search engines, students should not only be able to find the information but be able to apply the information effectively to accomplish a specific purpose ${ }^{[7]}$. To effectively use information students should have an ability to differentiate grey literature and standards from among other types of information, assess the relevance and credibility of the source to their application, and then apply the information to their project.

Based on informal assessment of students in a senior level mechanical engineering experimental design course, it was evident that students are usually aware of monographs and periodicals from introductory library instruction but are unable to differentiate these from grey literature and engineering standards. In response to this observation, and the growing need for engineering standards literacy, this study was initiated with the goals to

1) Develop a 50 minute lecture to inform engineering students of the different literature sources available, including grey literature and standards, differentiate between the forms, and when to apply them in context.

2) Investigate whether an in-class exercise requiring students to sort information based on type would influence the number and types of literature utilized in design reports.

Prior to analysis and publication of the results the research was found to be exempt from the need for IRB review by the Office of Research Assurances at Washington State University. 


\section{Instruction Methodology}

A senior level experimental design course in mechanical engineering was selected for the study due to an opportunity for control groups where the same instructor was teaching three sections of the class in parallel. The course includes three written technical reports in addition to oral reports and progress reports. The report writing format generally included 5 sections: introduction, literature review or background, theory, experiment, and discussion. Of additional significance is that this was the first discipline-specific library instruction the mechanical engineering students received. The spring 2014 test course included three independent sections of 18 students. Students are paired in each section during the experiments resulting in 9 reports per section.

The library instruction was designed for presentation after the first experiment prompt was assigned. Students at this point in their coursework are in an exploratory phase with their experimental equipment and design. The purpose of the library instruction was to give students the tools they need to design and analyze the experimental equipment. To give students those tools the library instruction included a review of the library catalog and library article databases. The class regularly met for a three hour lab session twice a week. The instructor designated one three hour lab time for a one-shot 50 minute lecture with an additional two hours of librarianassisted work time.

By a student's senior year they have become familiar with academic or scholarly writing. However, to show the influence literature searching can have in the corporate arena the library session began with examples of opening statements without citations as shown in Figure 1. The librarian and instructor then engaged the students in a discussion about what would increase the relevance and credibility of the opening statements. During this discussion the ability to show statistics and research behind a concept is discussed as being influential in decision making. After a brief discussion the students were shown the same opening statements with the addition of citations as shown in Figure 2. The instructor of the course instructs students that finding and ultimately including citations can strengthen the credibility of any report.

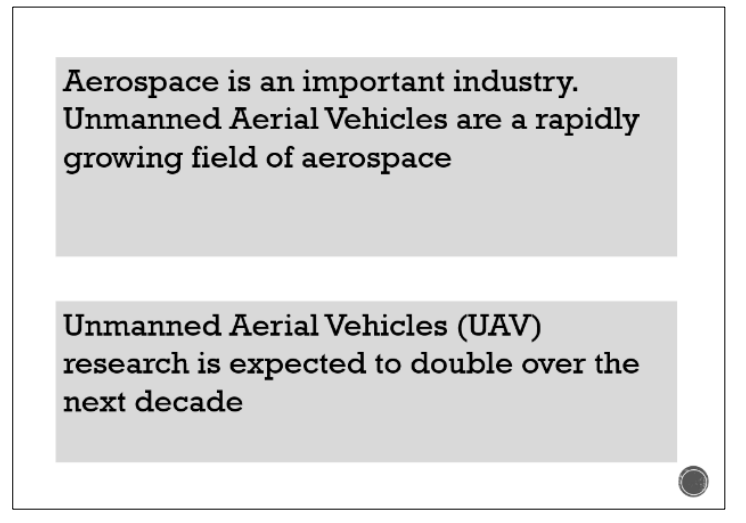

Figure 1: Example opening introductory sentences lacking citable statistics and sources.
Aerospace is an important industry. Unmanned Aerial Vehicles are a rapidly growing field of aerospace projected to create 10,000 jobs during 2014 (Bureau of Labor Statistics 2013)

Unmanned Aerial Vehicles (UAV) research is expected to double over the next decade to $\$ 11.5$ billion in expenditures (Teal Group 2010).

Figure 2: Example opening introductory sentences including citable statistics and sources. 
Once the influence of citations was established the librarian continued with the review of different types of information. The types of information presented to students, Figure 3, were books, articles, grey literature, and multimedia. Beyond the identification of grey literature many of the students were already familiar with the types of information. At this point in the instruction the control sections of the course continued with a typical demonstration of library databases and search engine strategies.

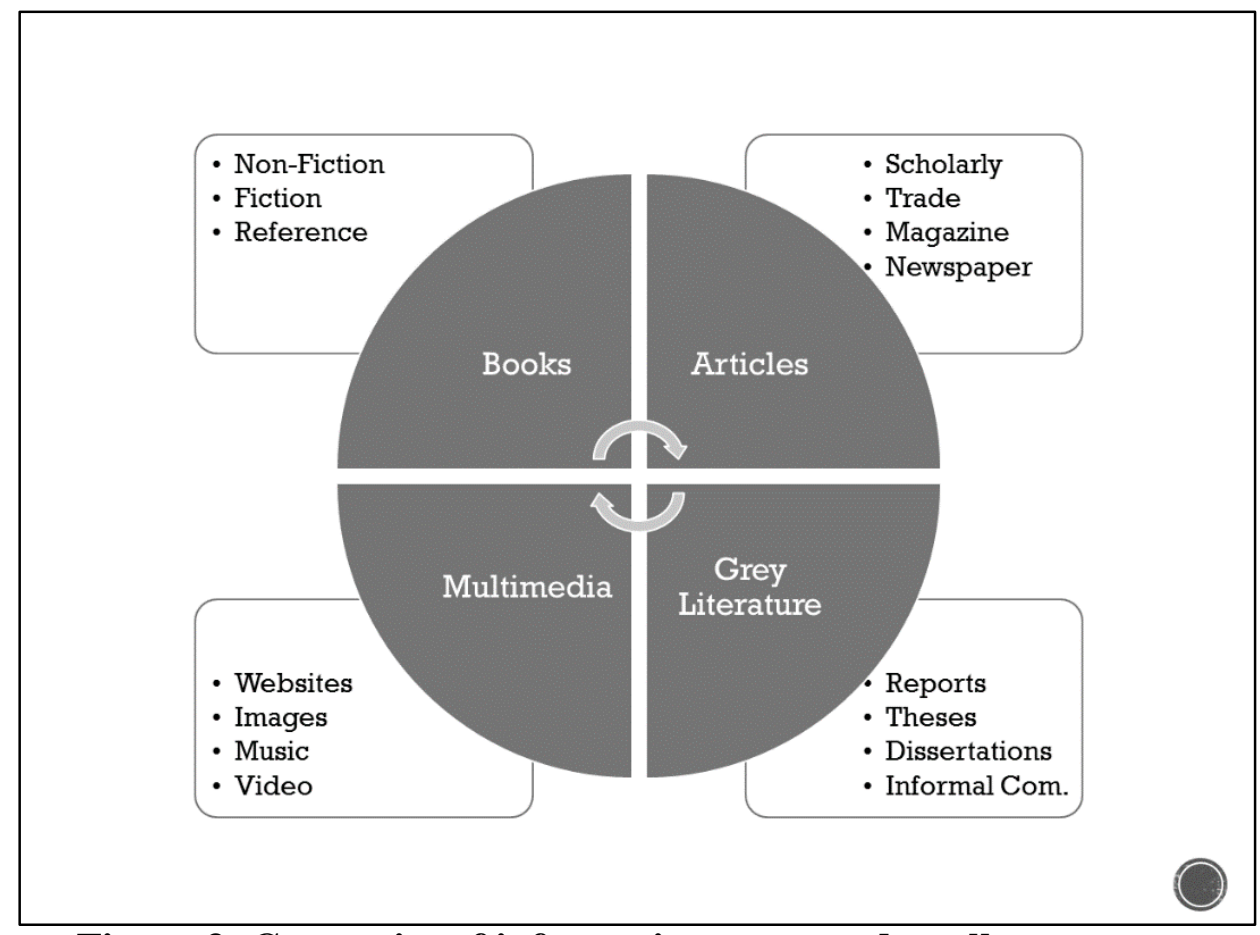

Figure 3: Categories of information presented to all course sections.

For the test section of the course the information types were presented in the context of their assignment layout, Figure 4. In addition to placing the general type of information into the context of their assignment an example was presented to the test section on the topic of the Tacoma Narrows Bridge collapse, Figure 5. Afterwards the test section continued with the same library database, search engine strategies demonstration as the control sections.

After presenting the sources within the context of the assignment outline the students in the test section were also required to complete a worksheet. The worksheet, Appendix A, had students follow the outline provided by the instructor and identify an information source that would fit that topical area within their report. 


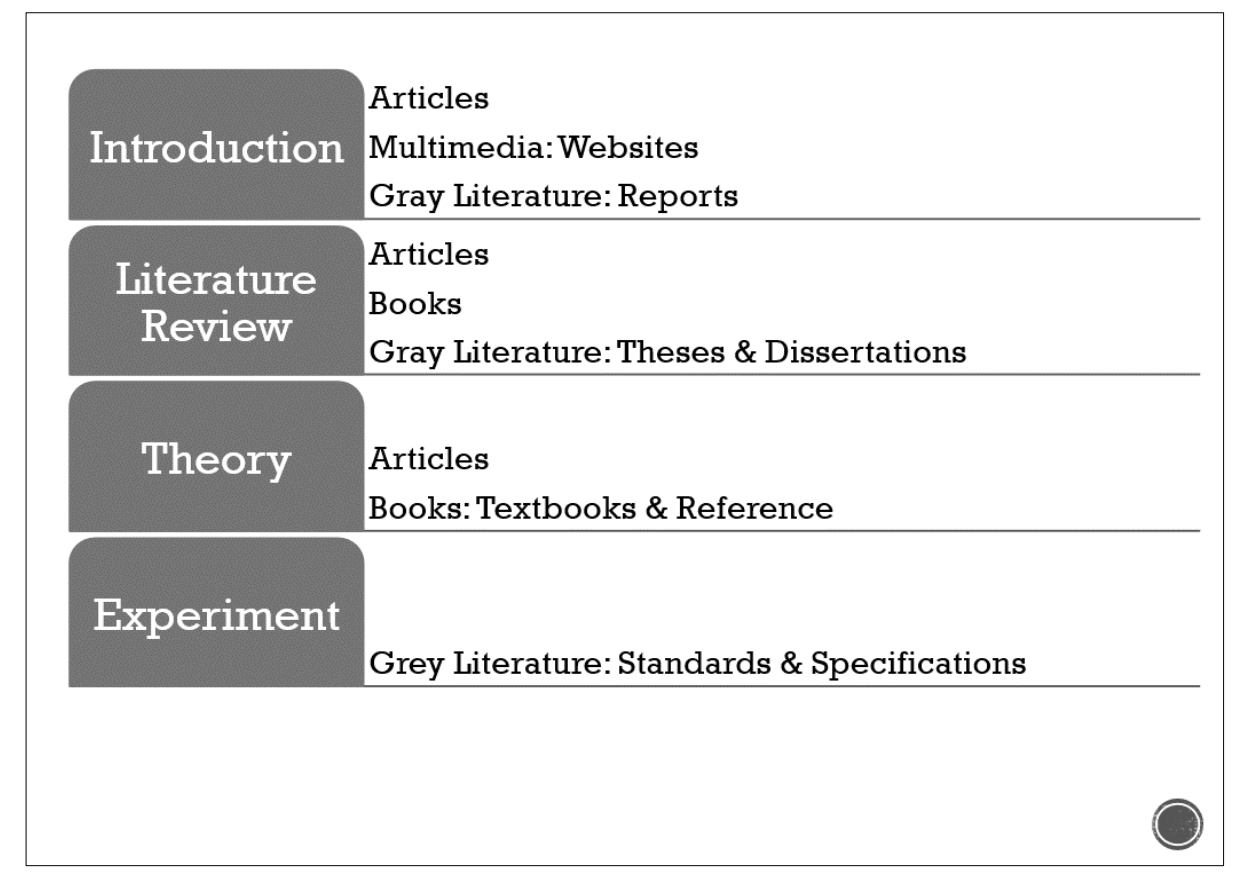

Figure 4: Categories of information placed into likely position of report based on context and only presented to test section.

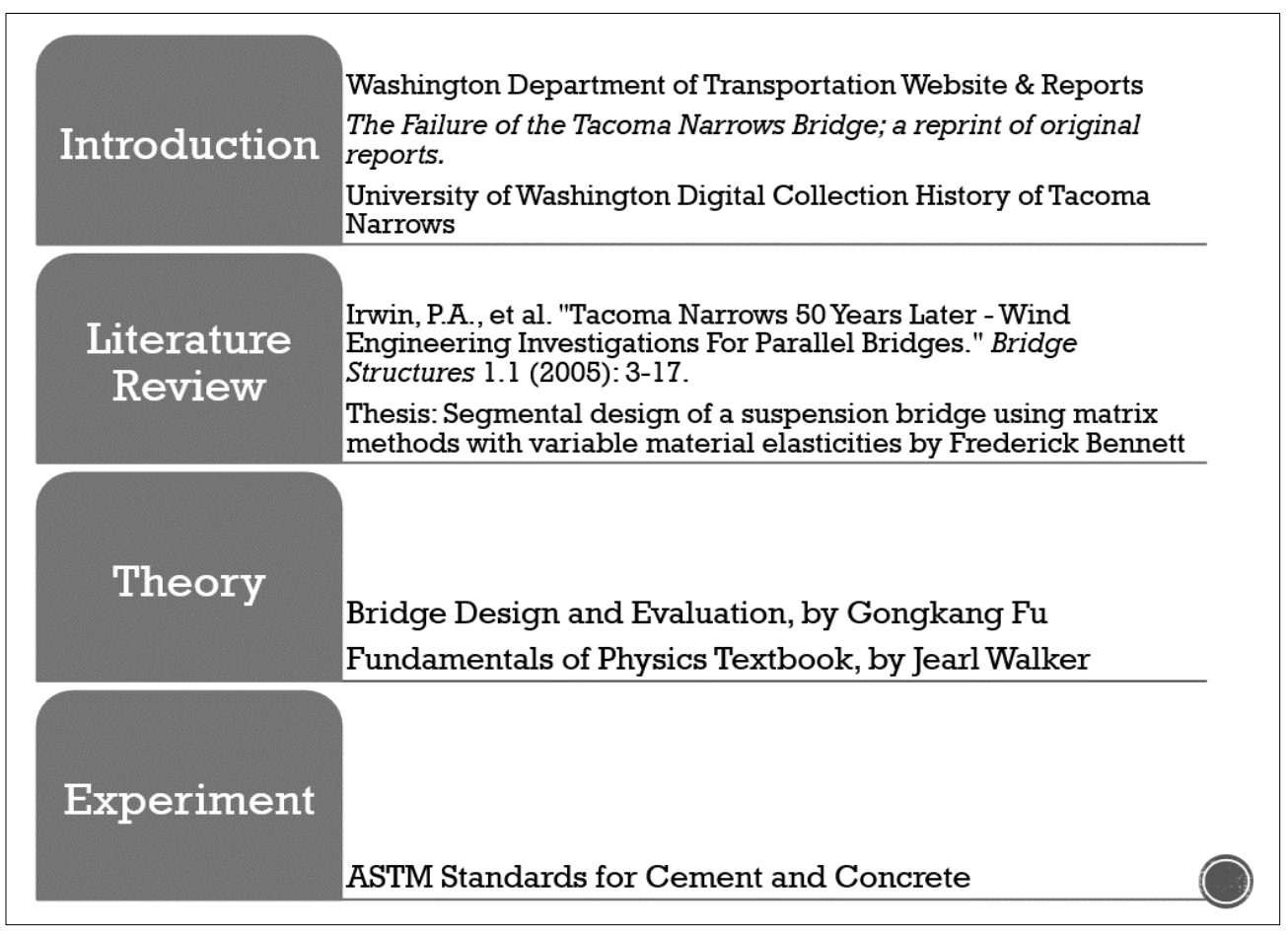

Figure 5: Example of a completed worksheet with literature sources placed into context for a hypothetical report on the Tacoma Narrows bridge collapse. This was only presented to the test section. 
Impact of Instructional Methodology

Completed reports were collected for each section. Report citations were coded into five areas of information type: multimedia, books, articles, grey literature, and standards. Although standards would typically be associated with grey literature, they were coded separately here since standards use was of particular interest. Table 1 shows the average citation count by information type for the control, test, and different faculty sections, including the percentage change from control to test for the same instructor, and the standard deviation over all literature types.

Since the class is taught every semester by multiple faculty, the influence of the engineering faculty member responsible for teaching the course is an additional variable of consideration for the experiment. To test this influence on citation counts, the same librarian presented the same content as was presented to the test section to two additional sections of the course during the fall semester of 2014. These additional sections were taught by two different faculty members (labeled B and C in Table 1). However, due to time constraints in the additional sections, the student worksheet requiring listing of the found sources by report section could not be completed by the students and presents an additional variable. Thus additional sections taught by other engineering faculty instructors are labeled "Modified Test".

Table 1: Average citation count based on literature type for the control, test, and variation with engineering faculty. The percentage change from original control included for the same faculty along with the standard deviation over all literature types.

\begin{tabular}{|c|c|c|c|c|}
\hline & $\begin{array}{c}\text { Spring 2014 } \\
\text { Control } \\
\text { (Instructor A) }\end{array}$ & $\begin{array}{c}\text { Spring 2014 } \\
\text { Test } \\
\text { (Instructor A) }\end{array}$ & $\begin{array}{c}\text { Fall 2014 } \\
\text { Modified Test } \\
\text { (Instructor B) }\end{array}$ & $\begin{array}{c}\text { Fall 2014 } \\
\text { Modified Test } \\
\text { (Instructor C) }\end{array}$ \\
\hline Multimedia & 1.11 & $0.67(-40 \%)$ & 2.25 & 2.40 \\
\hline Monographs & 1.11 & $1.33(+20 \%)$ & 1.25 & 1.00 \\
\hline Articles & 0.94 & $1.22(+29 \%)$ & 0.25 & 0.30 \\
\hline Grey Literature & 0.67 & $1.22(+83 \%)$ & 2.83 & 0 \\
\hline Standards & 0.84 & $0.67(-20 \%)$ & 0.25 & 5.70 \\
\hline Average Total & 4.78 & $5.11(+7 \%)$ & 6.83 & 0 \\
\hline
\end{tabular}

For the three sections taught by the same faculty member, the overall number of citations increased only slightly between controls and the test section. The largest change is the increase of $83 \%$ in grey literature use between the control and test sections. Of the grey literature used in the test section $55 \%$ were company produced product manuals, $18 \%$ government documents, $18 \%$ technical papers, and $9 \%$ theses. The control section used $42 \%$ company produced product manuals, $42 \%$ government documents, and $18 \%$ technical papers. While there was not an increase in the use of standards, more than $50 \%$ of the groups in each section applied standards 
to their experiments. The standards used were 47\% ASME standards for the control section and $67 \%$ ASME standards for the test section. Other standards that were used were SAE, ASHRAE and AES standards. The use of multimedia was all third party personal or consumer websites with low to no creditability, decreased by $40 \%$. Monograph usage only increased by $20 \%$ and article use increase $29 \%$ in the test section. Of the articles used over $90 \%$ in all groups were journal articles.

Two subsequent sections of the course taught by other engineering faculty were analyzed to determine the influence of faculty member with similar librarian instruction. The citation average increased within both sections. However, this increase is directly associated with an increase in the use of multimedia. Although a substantial increase in the use of grey literature was observed, this grey literature was $68 \%$ company user manuals, $15 \%$ government documents, $9 \%$ technical papers, and $7 \%$ theses. A decrease in the use of standards was observed in both sections with no standards use in one section. The increase in multimedia and decrease in standards use could be attributed to student expectations as communicated by faculty.

Preliminary results indicate that simply presenting information types and placing them into context within a report is not effective at increasing the overall quality of student citations, as measured by standards use. Although a difference was observed between the test and control condition for the same faculty member, the improvement was not observed when tested on other engineering faculty where the students reverted to lower quality source content (multi-media and company brochures) despite the similar librarian lecture content.

One interesting observation is the effect of the worksheet requiring the test section to list found sources within the planned use section of their report. An expectation was that the worksheet (test) section would see greater diversity of citation use, which was observed compared to the modified test sections taught by other engineering faculty. However the worksheet (test) section had less diversity than the control sections taught by the same faculty, indicating that the worksheet was not effective at increasing diversity and quality of literature use.

\section{Conclusions and Future Research}

With academic research heavily focused on the use of scholarly articles this instructional method introduces a different way of presenting literature types, emphasizing grey literature and standards, within a discipline specific course. Efforts to increase the use of standards among other information types, by implementing an in-class worksheet and example presentation, were not observed to be effective with this small sample size. The engineering faculty member in charge of the class has a much larger effect on the diversity and quantity of standards used in the student reports. Reasons for this discrepancy among faculty members are currently unclear as the course syllabus and experiments are the same across course sections, however this could point to differences in faculty expectations communicated to the students. The variation among test sections underscores the difficulties of developing effective educational methods to increase standards use. Given the importance of this in engineering education, additional research and efforts to scale the research to a statistically significant sample pools are recommended. 
[1] Commission, E.A.," Criteria for accrediting engineering programs", ABET Report E001 11/7/14, 2014.

[2] Amercian Society of Mechanical Engineers, "Standards \& Certification FAQ".

[3] Allen, R.H., and R.D. Sriram," The role of standards in innovation", Technological Forecasting and Social Change Vol. 64, No. 2, 2000, pp. 171-181.

[4] Grey Literature International Steering Committee, "Guildlines for the production of scientific and technical reports: how to write and distribute grey literature", 1997.

[5] Waters, N., E. Kasuto, and F. McNaughton," Partnership between engineering libraries: Identifying information literacy skills for a successful transition from student to professional", Science and Technology Libraries Vol. 31, No. 1, 2012, pp. 124-132.

[6] Robbins, S., D. Engel, and C. Kulp," How unique are our users? Comparing responses regarding the information-seeking habits of engineering faculty", College \& Research Libraries Vol. 72, No. 6, 2011, pp. 515-532.

[7] Association of College and Research Libraries, "Information Literacy Competency Standards for Higher Education", Chicago, Illinois: American Library Association, 2000. 


\section{APPENDIX A: INFORMATION CONTEXT WORKSHEET}

1. Literature Review

Title

Authors(s)

Resource Type

○ Book

- Article

- Grey Literature

- Standard

2. Theory

Title

Authors(s)

Resource Type

○ Book

- Article

- Grey Literature

- Standard

3. Experiment

Title

Authors(s)

Resource Type

o Book

- Article

- Grey Literature

- Standard 